\title{
Acquired prothrombin complex deficiency: Case reports
}

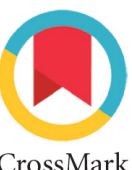

\author{
Heri Puguh Widodo ${ }^{1 *}$, Novan Krisno Adji ${ }^{1}$
}

'Department of Neurosurgery, Soebandi General Hospital, Universitas Jember, Jember, Indonesia.

\section{*Corresponding to:}

Heri Puguh Widodo; Department of Neurosurgery, Soebandi General Hospital, Universitas Jember, Jember, Indonesia; Email: heripuguhwidodo@ gmail.com

Received: 2020-12-22

Accepted: 2021-07-29

Published: 2021-08-13

\section{ABSTRACT}

Introduction: Acquired prothrombin complex deficiency (APCD) is a spontaneous hemorrhage due to decreased activity of vitamin $\mathrm{K}$ dependent coagulation factor (factor II, VII, IX, and X). Many factors lead to vitamin K deficiency in newborns. We reported case reports of APCD which were successfully managed with APCD guidelines.

Case presentation: First case was baby aged 1 month who came to emergency ward due to seizure four times. Seizures were occurred for 30 minutes and reported unconscious between episode of seizure. Head computed tomography (CT) scan examination revealed crescent shape appearance which suggested subdural hematoma (SDH). Second case was a 2 months old baby came to emergency department unconsciously since two days before. Patient has no history of vomiting and seizures. Non-contrast head CT scan showed appearance of crescent shape, which suggested presence of SDH. Both patients were managed according to APCD guidelines and had improved.

Conclusion: Mild APCD has good prognosis and showing improvement in 24 hours after vitamin $\mathrm{K}$ injection. The mortality rate is very high in case of severe bleeding in intracranial, intrathoracic, and intraabdominal.

Keywords: acquired prothrombin complex deficiency, hemorrhagic disease of the newborn, subdural hematoma, vitamin K deficiency

Cite This Article: Widodo, H.P., Adji, N.K. 2021. Acquired prothrombin complex deficiency: Case reports. Indonesian Journal of Neurosurgery 4(2): 69-71. DOl: 10.15562/ijn.v4i1.90

\section{INTRODUCTION}

Acquired prothrombin complex deficiency (APCD) is a disorder characterized by spontaneous bleeding due to decreased activity of vitamin $\mathrm{K}$ dependent coagulation factor (factor II, VII, IX, and $\mathrm{X}) .{ }^{1}$ Other coagulation factors such as fibrinogen and platelet levels are within normal limits. APCD is also known as vitamin $\mathrm{K}$ deficiency bleeding (VKDB) or hemorrhagic disease of newborn (HDN). APCD usually occurs at age of 8 days to 6 months with the highest incidence at $3-8$ weeks of age..$^{2,3}$ Based on the onset, APCD is divided into early, classical, and slow type. ${ }^{4}$

Incidence rate of APCD is 4 to 25 cases per 1 million births in Western countries and 25 to 80 cases per 1 million births in Eastern countries. The highest reported cases of APCD is in Japan and Thailand. In Thailand, incident of APCD was 35.5 per 1 million births in 1966 . The mortality rate in Asia reaches 1:1200 to 1:1400 births and could reaches 1:500 births in regions that not routinely administer prophylactic vitamin $\mathrm{K}$ in newborns. Epidemiological data of APCD in Indonesia is not available yet. Until 2004, there were 21 cases in Cipto Mangunkusomo hospital, 6 cases in Dr. Sardjito hospital, and 8 cases in Dr. Soetomo hospital.

Neonates is unable to produce vitamin $\mathrm{K}$ from gastrointestinal tract. Vitamin $\mathrm{K}$ is a fat soluble vitamin, which is required in the synthesis process of pro coagulant factors (factor II, VII, IX, and $\mathrm{X}$ ) and $\mathrm{C}$ and $\mathrm{S}$ proteins, which act as anticoagulants. Unavailability of vitamin $\mathrm{K}$ leads to coagulopathy, which triggers life-threatening spontaneous bleeding. Intracerebral hemorrhage (ICH) often occurs in infants with APCD. ICH due to idiopathic vitamin $\mathrm{K}$ deficiency is still a problem even in the era of prophylactic vitamin K. ICH in early days of children is a serious bleeding because of high mortality rate and permanent neurological damage. ${ }^{2}$

\section{CASE PRESENTATION}

\section{Case 1}

A 48-day old baby came to the emergency department with chief complain of seizure at home. Seizures were occurred three times and lasting for less than 10 minutes. Patient was reported unconscious between episode of seizures. Seizures occurred concurrently with fever. At previous day, the patient experienced vomiting and was taken to a clinic. In the emergency department, patient experience a seizure and loss of consciousness. The patient had no history of trauma.

During pregnancy, there was no history consuming any medications such as anticonvulsion, anti-tuberculosis, antibiotics, or anticoagulants. Patient was born term and no complications were encountered during delivery process. Patient was given exclusive breast feeding within 48 days post delivery.

On physical examination, quality of consciousness was 112 in pediatric Glasgow coma scale (pGCS). The pupils were equally $3 \mathrm{~mm}$ and non-reactive to light. Head computed tomography (CT) scan examination revealed crescent shape appearance which suggested subdural hematoma (SDH) (Figure 1). 
The laboratory result of patient can be seen Table 1. The patient was performed craniotomy to evacuate the SDH in the third day of admission. Patient was administered $1 \mathrm{mg}$ of vitamin $\mathrm{K}$ intramuscular on first day to third day of admission.

Table 1. Laboratory value of first case in emergency department

\begin{tabular}{lc}
\multicolumn{1}{c}{ Parameter } & Value \\
\hline Hemoglobin & $5.4^{*}$ \\
Leukocyte & 10.6 \\
Hematocrit & $15.1^{*}$ \\
Thrombocyte & 404 \\
Prothrombin time & \\
$\quad$ Patient & $11.8^{*}$ \\
Control & 9.7 \\
Activated partial thromboplastin & \\
time & 29.8 \\
Patient & 29.1 \\
Control & \\
\hline
\end{tabular}

*Abnormal value

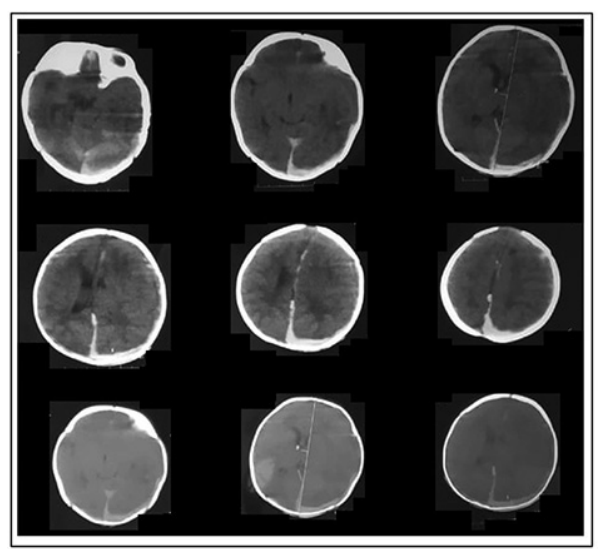

Figure 1. Non contrast head CT scan showed appearance of subdural hematoma in first case.

\section{Case 2}

A 2 months old baby came to emergency department unconsciously since two days before. Patient has no history of vomiting and seizures. No history of head trauma. During pregnancy, there was no history consuming any medications such as anti-convulsion, anti-tuberculosis, antibiotics, or anticoagulants. Patient was born at 38 weeks of gestational age and no complications were encountered during delivery process. Patient was given exclusive breast feeding.

On physical examination, quality of consciousness was 111 in pGCS. There was no response in eye, verbal, and motor function. The pupils were equally $3 \mathrm{~mm}$ in diameter and non-reactive pupillary reflex. Non-contrast head CT scan showed appearance of crescent shape, which suggested presence of SDH (Figure 2). The value of laboratory parameter can be seen in Table 2 The patient was performed craniotomy to evacuate the SDH in the third day of admission. Patient was administered $1 \mathrm{mg}$ of vitamin $\mathrm{K}$ intramuscular on first day to third day of admission. This patient was administered additional transfusion of $40 \mathrm{cc}$ fresh frozen plasma (FFP) on the second day of admission.

\section{Table 2. Laboratory value of second case in emergency department}

\begin{tabular}{lc}
\multicolumn{1}{c}{ Parameter } & Value \\
\hline Hemoglobin & $10.3^{*}$ \\
Leukocyte & 11.9 \\
Hematocrit & $29.1^{\star}$ \\
Thrombocyte & 374 \\
Prothrombin time & \\
$\quad$ Patient & 9.1 \\
$\quad$ Control & 9.7 \\
Activated partial thromboplastin & \\
time & $19.6^{*}$ \\
$\quad$ Patient & 29.1 \\
Control & \\
\hline
\end{tabular}

${ }^{\star}$ Abnormal value

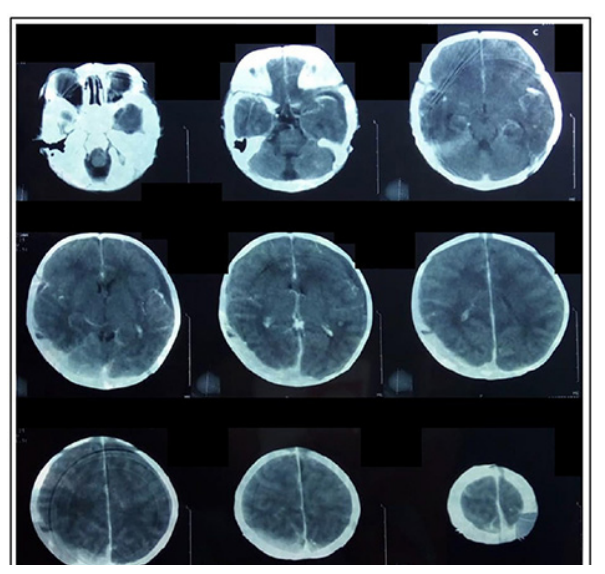

Figure 2. Non contrast head CT scan showed appearance of subdural hematoma in second case.

\section{DISCUSSION}

Acquired prothrombin complex deficiency (APCD) is a disorder characterized by spontaneous bleeding due to decrease activity of vitamin $\mathrm{K}$ dependent coagulation factors (factor II, VII, IX, and $\mathrm{X}$ ). Other coagulation factors such as fibrinogen and platelet levels are within normal limits. APCD is also known as vitamin $\mathrm{K}$ deficiency bleeding (VKDB) or hemorrhagic disease of newborn (HDN). APCD usually occurs at age of 8 days to 6 months with the highest incidence at $3-8$ weeks of age. ${ }^{2,3}$

In addition to APCD, shaken baby syndrome (SBS) is also included in a condition characterized by spontaneous bleeding. SBS is also referred to shaken infant syndrome and abusive head trauma. On SBS, neonates are usually carried on the shoulder, torso, or chest and followed by a movement of body shaking back and forward. These movement can cause serious injury even in short time. Neonates have weaker anatomical structure, especially in the neck muscles. Therefore, it is prone to non-accidental head injury. One mechanism is the presence of whiplash-like injury as a result of acceleration-deceleration. ${ }^{5}$

APCD and SBS are clinically similar. However, the level of coagulation factors is the fundamental difference between them. In APCD, prothrombin time and activated partial prothrombin time are longer and accompanied by low activity of coagulation factors (factor II, VII, IX, and $\mathrm{X}$ ), which is below $30-35 \%{ }^{2,5}$

In our cases, we did not find any risk factors that contribute to the onset of APCD such as consuming medications that interfere metabolism of vitamin $\mathrm{K}$ during pregnancy. The medications are anti-convulsant (carbamazepine, phenobarbital, and phenytoin), antibiotics (cephalosporin), anti-tuberculosis (INH, rifampicin), and anti-coagulant (warfarin). Pregnant women who consuming those medicines should be administered prophylactic vitamin $\mathrm{K} 1$ with dose of $5 \mathrm{mg}$ per day during third semester of pregnancy or $10 \mathrm{mg}$ intramuscular at 24 hours before delivery. The baby should also be administered vitamin K1 $1 \mathrm{mg}$ intramuscular and repeated 24 hours later. There were no other conditions that interfere synthesis and absorption of vitamin $\mathrm{K}$ in the intestines such as alpha- 1 anti-trypsin deficiency, biliary atresia, celiac disease, chronic diarrhea, cystic fibrosis, and cholestasis.

Both patients were given exclusive 
breast feeding. Exclusive breast feeding within 6 months without administration of prophylaxis vitamin $\mathrm{K}$ increased occurrence of APCD. In breast milk, the content of vitamin $\mathrm{K}$ is less than $5 \mathrm{mg} / \mathrm{ml}$, which is lower than formula milk (50 - 60 $\mathrm{mg} / \mathrm{mL}$ ). Bacteria Bacteroides fragilis are present in the intestine of formula milk feeding infant, which are able to synthesize vitamin $\mathrm{K}$. On the other hand, in breast feeding infant, there are Lactobacillus bacteria, which are not able to synthesize vitamin $\mathrm{K}$.

The American Academy of Pediatric (AAP) recommended administration of single dose vitamin $\mathrm{K}$ at $0.5-1 \mathrm{mg}$ intramuscular as prophylaxis in all newborn infants. Vitamin $\mathrm{K}$ injection works through two mechanisms. First, by entering bloodstream and increasing vitamin $\mathrm{K}$ levels in the blood. Therefore, level of vitamin $\mathrm{K}$ in infant is maintained at first days of life. Vitamin $\mathrm{K}$ will be stored in liver and may be used to activate coagulation factor. Second, vitamin K is released slowly for $2-3$ months to maintain the level of vitamin $\mathrm{K}$ until it can be obtained from the diet. In our cases, only one patient who did not administered prophylactic vitamin $\mathrm{K}$.

Both patients were administered vitamin $\mathrm{K}$ injection with dose of $1 \mathrm{mg}$ for 3 days. However, only the second patient who had additional transfusion of FFP $40 \mathrm{cc}$. This was in accordance to APCD guidelines, that administration of vitamin $\mathrm{K}$ injection with dose of $1-2 \mathrm{mg}$ per day for $1-3$ days should be given to infants with suspected APCD. FFP can be administered with dose of $10-15 \mathrm{ml}$ per $\mathrm{kg}$ in infants with extensive bleeding while increasing vitamin $\mathrm{K}$ dependent coagulation factor by $0.1-0.2$ unit per $\mathrm{ml}$. The treatment is expected to response at $4-6$ hours after the injection, which is marked by the cessation of bleeding and improved coagulation parameter. If no improvement is happened within 24 hours, other causes should be suspected.

Neonates with intracranial bleeding should be managed in three stages. The first stage is maintaining airway, breathing, and circulation. Neonates without impaired consciousness may be given supportive therapy only. However, those with moderate degree of impaired consciousness, respiratory distress, or unstable hemodynamic may require advanced airway management to provide adequate oxygenation and ventilation. Oxygenation can be monitored with pulse oximeter.

The main treatment of severe intracranial bleeding is to treat the primary brain injury and preventing secondary brain injury. Regulation of intracranial pressure (ICP) is important to prevent secondary brain damage. One of methods to decrease ICP is hyperventilation to keep $\mathrm{PaCO}_{2}$ in the range of $25-30 \mathrm{mmHg}$. Elevation of head for 30 degrees is another way to optimize cerebral perfusion pressure and decreases ICP by increasing venous return without affecting cerebral blood flow. ${ }^{6}$

Intracranial bleeding could cause intracranial hypertension. Appropriate treatment is required to prevent increasing in ICP. The goal is keeping the ICP below $20 \mathrm{mmHg}$ and the cerebral perfusion pressure (CPP) above $40 \mathrm{mmHg}$. Normal CPP values of each age are different, for example $50 \mathrm{mmHg}$ in 2 - 6 years old, 55 $\mathrm{mmHg}$ in $7-10$ years old, and $60 \mathrm{mmHg}$ in $11-16$ years old. Administration of hypertonic agents should be considered in moderate degree of increasing ICP. $\mathrm{NaCl}$ $3 \%$ bolus $(2-6 \mathrm{ml} / \mathrm{kg}$ ) can be administered and followed by maintenance dose $(0.1$ - $1 \mathrm{ml} / \mathrm{kg} /$ hour) until sodium level reach $155 \mathrm{gr} / \mathrm{dl}$ or serum osmolality reach 360 $\mathrm{mOsm} / \mathrm{L}$. Another option is administering mannitol $(0.25-1$ gram $/ \mathrm{kg})$ intravenous every $4-6$ hours with upper limit of 320 $\mathrm{mOsm} / \mathrm{L}$ in serum osmolality. Patients with persistent high ICP require sedation with barbiturates to decreased ICP by reducing cerebral metabolism and cerebral blood flow. In addition, slight hypothermia $\left(32-33^{\circ} \mathrm{C}\right)$ for 48 hours can also decrease brain metabolism. In the presence of herniation, neurological deterioration, or not responding to previous therapy, decompressive craniectomy should be performed. ${ }^{6}$

In our cases, after receiving treatment according to APCD guidelines, the condition had improved and discharged with pGCS 456. Generally, mild APCD has good prognosis and showing improvement in 24 hours after vitamin $\mathrm{K}$ injection. The mortality rate is very high in case of severe bleeding in intracranial, intrathoracic, and intraabdominal.

\section{CONCLUSION}

Mild APCD has good prognosis and showing improvement in 24 hours after vitamin $\mathrm{K}$ injection. The mortality rate is very high in case of severe bleeding in intracranial, intrathoracic, and intraabdominal. Future research should examine contribution of other factors such as timing in administration of vitamin $\mathrm{K}$ and skill of health worker regarding incidence of VKDB.

\section{CONFLICT OF INTEREST}

There is no conflict of interest related to the materials and methods used in this study.

\section{FUNDING}

This article did not receive any special funding from any capital agency.

\section{Author contribution}

The authors took part in research design, data collection, script-writing, and all authors agree to accept similar responsibilities against the accuracy of the content of this article.

\section{REFERENCES:}

1. Dewi LP, Nurfitri E, Evodia E, Romli MT. Good outcomes in operative management of acquired prothrombin complex deficiency: a serial case report. Paediatrica Indonesiana. 2011; 51(5): 298 - 302. https://doi.org/ 10.14238/ pi51.5.2011.298-302.

2. Jain $\mathrm{S}$, Acharya SS. Bleeding risk with vitamin $\mathrm{k}$ deficiency. Transf Med Hemost. 2019; 729 - 733.

3. Rech MA, Wittekindt L, Friedman SD, Kling K, Ubogy D. Prothrombin complex concentrate for intracerebral hemorrhage secondary to vitamin $\mathrm{k}$ deficiency bleeding in a 6-week-old child. J Pediatr. 2015; 167(6): 1443 - 1444. https://doi.org/ 10.1016/j.peds.2015.09.030.

4. Ismy J. Dua kasus acquired prothrombin complex deficiency dengan perdarahan intrakranial: laporan kasus. Jurnal Kedokteran Syiah Kuala. 2017; 17(3): 174 - 178.

5. Cabrera G, Schub T. Shaken baby syndrome. Cinahl Information Systems. 2017; 1 - 3. Available from: https://www.ebscohost.com/ assets-sample-content/NRC_QL_Shaken Baby Syndrome.pdf

6. Hung K-L. Pediatric abusive head trauma. Biomedical J. 2020: 43(3): 240 - 250. https://doi. org/10.1016/j.bj.2020.03.008

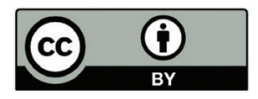

This work is licensed under a Creative Commons Attribution 